\title{
Probable gas embolism during operative hys- teroscopy caused by products of combustion
} [Probabilité d'embolie gazense causée par des produits de combustion pendant l'hystéroscopie peropératoire]

Ngozi Imasogie FRCA, Ron Crago FRCPC, Nicholas A. Leyland FRCSC, Frances Chung FRCPC

Purpose: Gas embolism is a rare but well documented entity during operative hysteroscopy, with an incidence of 10-50\%. Catastrophic outcomes occur at a rate of three in 17,000 procedures. The purpose of this report is to present a non-fatal case of gas embolism probably caused by the gaseous products of combustion.

Clinical features: A 50-yr-old woman with a history of menorrhagia was scheduled for hysteroscopy and endometrial ablation and polypectomy. Fifteen minutes into the procedure, with the patient in lithotomy position, $20^{\circ}$ head down tilt, and breathing spontaneously, a sudden oxygen desaturation occurred from $97 \%$ to $87 \%$. The patient's end-tidal carbon dioxide dropped from 46 $\mathrm{mmHg}$ to $27 \mathrm{mmHg}$. The patient's breathing pattern remained normal, respiratory rate remained $11-12$ breaths $\cdot \mathrm{min}^{-1}$ but amplitude of the reservoir bag movement was increased. Cardiovascular variables remained stable. She responded rapidly to 100\% oxygen and made an uneventful recovery. Having ruled out other possible causes, we concluded gas embolism was responsible for the fall in oxygen saturation and end-tidal $\mathrm{CO}_{2}$.

Conclusion: With all the precautions in place to minimize the likelihood of fluid overload and ambient air embolism occurring, we surmised that products of combustion were the cause of the gas embolism. During endometrial ablation, gaseous products of combustion, mainly carbon dioxide, accumulate. The gases may then contribute to the rise in uterine pressure that occurs as irrigation fluid enters the uterus and this rise in pressure in turn encourages passage of gas into the open venous sinuses.

Objectif : L'embolie gazeuse est un état pathologique rare, mais bien documentée, survenant pendant l'hystéroscopie peropératoire selon une incidence de 10-50\%. Des conséquences catastrophiques surviennent dans trois interventions sur 17 000. Nous avons voulu présenter un cas d'embolie gazeuse non mortelle causée probablement par des produits de combustion gazeux.

Éléments cliniques : Une femme de 50 ans présentant des antécédents de ménorragie devait subir une hystéroscopie et l'ablation de l'endomètre ainsi qu'une polypectomie. Quinze minutes après le début de l'opération, la patiente en position de lithotomie, avec inclinaison de $20^{\circ}$ et tête vers le bas, respirait spontanément quand est survenue une soudaine désaturation en oxygène qui est passé de $97 \%$ à $87 \%$. Le gaz carbonique télé-expiratoire du patient a chuté de $46 \mathrm{mmHg}$ à 27 $\mathrm{mmHg}$. Le type de respiration est demeuré normal, le rythme respiratoire était de $11-12$ respirations $\cdot \mathrm{min}^{-1}$, mais l'amplitude du mouvement du sac-réservoir a augmenté. Les variables cardiovasculaires étaient stables. La patiente a réagi rapidement à l'administration de $100 \%$ d'oxygène et s'est bien rétablie. Après avoir exclu d'autres causes possibles, nous avons conclu qu'une embolie gazeuse avait causé la chute de saturation en oxygène et le $\mathrm{CO}_{2}$ télé-expiratoire.

Conclusion : Considérant toutes les précautions mises en place pour minimiser la probabilité d'une surcharge liquide et d'une embolie à l'air ambiant, nous avons supposé que les produits de combustion étaient la cause de l'embolie gazeuse. Pendant l'ablation de l'endomètre, des produits de combustion gazeux, surtout du gaz carbonique, s'accumulent. Les gaz peuvent ainsi contribuer à l'élévation de la pression utérine qui survient au moment où le liquide d'irrigation pénètre dans l'utérus. Cette hausse de pression favorise le passage de gaz dans les sinus veineux.

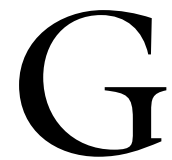
AS embolism during operative hysteroscopy is a rare but well described entity ${ }^{1-12}$ with an incidence ranging from $10-50 \% .^{2,3}$ The true incidence is not known but catastrophic outcomes occur at a rate of three in 17,000 procedures. ${ }^{13}$ The source of the gas

From the Department of Anesthesia, Toronto Western Hospital, University Health Network, University of Toronto, Toronto, Ontario, Canada.

Address correspondence to:Dr. Ron Crago, Department of Anesthesia, Toronto Western Hospital, 399 Bathurst Street, Toronto, Ontario

M5T 2S8, Canada. Phone: 416-603-5118; Fax: 416-603-6494; E-mail: ron.crago@uhn.on.ca

Accepted for publication April 25, 2002.

Revision accepted August 14, 2002. 
may be ambient air which enters the uterine cavity during the procedure, ${ }^{13-15}$ or air bubbles within the distension fluid. ${ }^{13,15}$ Alternatively, the embolic gas may be carbon dioxide and carbon monoxide, evaporative products of combustion as surgery proceeds. ${ }^{2,13}$ In this case report we describe a non-fatal case of gas embolism which we think was due to gaseous products of combustion.

\section{Case report}

A 50-yr-old, $76.5 \mathrm{~kg}$ woman, with a history of menorrhagia, was scheduled for hysteroscopy, endometrial ablation and polypectomy in our ambulatory surgical unit. She had a past medical history of hypertension being treated with guinapril hydrochloride $10 \mathrm{mg}$ daily. The patient was allergic to sulphonamides. Her past surgical history included uneventful hemorrhoidectomy and a dilatation and curettage. Her physical examination was unremarkable. The electrocardiogram and complete blood count were within normal limits $\left(\mathrm{Hb} 137 \mathrm{~g} \cdot \mathrm{L}^{-1}\right)$. A preoperative medication of oral naproxen $500 \mathrm{mg}$ and $i v$ cefazolin $\mathrm{l} \mathrm{g}$ was given following insertion of an $i v$ cannula.

Monitoring was established with the electrocardiogram, non-invasive blood pressure, oxygen saturation $\left(\mathrm{SpO}_{2}\right)$ and end-tidal carbon dioxide $\left(\mathrm{ETCO}_{2}\right)$. Anesthesia was induced with fentanyl $100 \mu \mathrm{g}$, propofol $350 \mathrm{mg}$ (aliquots of 200, 50 and 100), followed by insertion of a size 4 laryngeal mask. Anesthesia was maintained with spontaneous breathing of nitrous oxide, oxygen and desflurane. The patient was placed in a lithotomy position with $20^{\circ}$ head down tilt prior to the start of surgery. The patient's vital signs were stable with oxygen saturation being $97-98 \%$ and $\mathrm{ETCO}_{2}$ 44-48 $\mathrm{mmHg}$. The cervix was dilated to $10 \mathrm{~mm}$ without difficulty and the last dilator was left in place until the Storz $10 \mathrm{~mm}$ fibreoptic resectoscope was ready for insertion into the uterus. The instrument, once inserted, delivers fluid distension medium and removes waste products simultaneously. The distension fluid Cystosol (sorbitol 3\%, mannitol $0.5 \%$ in water, Baxter) was supplied in $3 \mathrm{~L}$ bags and infused through $\mathrm{Y}$ connectors to allow change over without risk of air bubbles entering the system. The bags were placed not more than $1 \mathrm{~m}$ above the patient. Air bubbles were flushed out of the hysteroscope prior to insertion into the uterus.

Fifteen minutes after the start of surgery, there was a sudden and precipitous drop in $\mathrm{SpO}_{2}$ from 97 to $87 \%$ and $\mathrm{ETCO}_{2}$ dropped from $46 \mathrm{mmHg}$ to 27 $\mathrm{mmHg}$. The patient appeared to be developing cyanosis in spite of larger tidal volumes (the reservoir bag emptying more than at the start of the procedure). The respiratory rate remained 11-12 breaths. $\mathrm{min}^{-1}$ and the breathing pattern showed no signs of obstruction. The heart rate rose from 66 to 77 beats. $\mathrm{min}^{-1}$ and blood pressure increased to $94 / 63$ from $88 / 53 \mathrm{mmHg}$.

The surgeon was immediately informed, the procedure was rapidly completed and the patient returned to the supine position. Manually assisted ventilation was commenced with $100 \%$ oxygen. Auscultation of the chest was clear and no heart murmurs were heard. In less than five minutes, oxygen saturation rose to 96\% and the patient resumed spontaneous ventilation while emerging from anesthesia. In the postanesthesia care unit, the patient was awake and alert with blood pressure $122 / 73 \mathrm{mmHg}$, pulse 63 beats. $\mathrm{min}^{-1}$, respiratory rate 18 breaths. $\mathrm{min}^{-1}$, and $\mathrm{SpO}_{2} 99 \%$. The patient was observed for four hours in the ambulatory surgical unit and then discharged home.

\section{Discussion}

Pulmonary embolism occurs from a variety of causes: venous thrombus, amniotic fluid, fat, tumour, foreign body, and gases. Gases are particularly relevant during anesthesia, for example air embolus during neurosurgery and carbon dioxide embolus during laparoscopic surgical procedures. In the case reported here we believe gas, in the form of gaseous products of combustion, was the cause of the pulmonary embolism.

Gas embolism is a complication of hysteroscopy and was first reported in $1985 .{ }^{1}$ It is a potentially fatal complication in an otherwise healthy woman. ${ }^{2}$ In this patient, the sudden fall in both $\mathrm{ETCO}_{2}$ and $\mathrm{SpO}_{2}$, hallmarks of pulmonary embolism, suggested the diagnosis. As there was no measurable deficit in the input/output of the fluid used for distension, nor any signs suggestive of fluid overload, "female TURP syndrome" was ruled out as a differential diagnosis. We also eliminated obstructed ventilation since the event occurred acutely and the patient had been breathing normally for 15 min via a laryngeal mask airway. Gas embolism was thus thought to be the cause.

For gas embolism to occur, certain conditions have to be present: ${ }^{2}$ open venous channels in contact with gaseous medium, and an operating site above the level of the heart creating a pressure gradient. In the case of gas embolism, an added danger exists in that gas bubbles may cross to the systemic circulation either through the pulmonary vasculature or through a patent foramen ovale. If these paradoxical emboli are relatively insoluble (for example, air which is $80 \%$ nitrogen), they may cause ischemia and infarction in organs such as the heart and the brain. ${ }^{13,14}$

Whatever the cause of a pulmonary embolus, the pathophysiologic consequences are well known. When 
the embolus reaches the pulmonary circulation, it immediately creates lung regions with high ventilation/perfusion (V/Q) ratios (alveolar dead space) resulting in reduced end-tidal carbon dioxide. Pulmonary artery blood flow is diverted from embolized regions to unaffected lung regions which are then overperfused (lung regions with low $\mathrm{V} / \mathrm{Q}$ ratio); this shunt will result in hypoxemia and a decrease in oxygen saturation. Also, the opening of latent pulmonary arterial-venous shunts may contribute to the hypoxemia. The mechanical obstruction from the embolus causes a preload reduction to the left heart leading to possible hypotension. ${ }^{13}$

In the case presented, the source of the gas embolus may have been 1 ) ambient air, if the cervix and the uterus were left open to air after dilatation; ${ }^{14-16} 2$ ) air bubbles in the fluid distension medium; or 3 ) carbon dioxide, carbon monoxide and other particulate products of combustion. ${ }^{14,16}$ Open venous channels may be created during dilatation of the cervix for insertion of the hysteroscope; occult false passages may be created at the level of the internal os; or partial penetration into the myometrial wall may occur following forceful dilatation, leaving blood vessels open. ${ }^{2}$ Ambient air, pressurized gas such as $\mathrm{CO}_{2}$ distension gas, or gaseous products of combustion, may then enter the circulation. Dilatation to $10 \mathrm{~mm}$ did occur, however, the last dilator was left in place until the hysteroscope was ready for insertion, allowing minimal exposure of the cervix and uterus to room air. Dilatation was performed without difficulty, so false passage creation in the lower segment of the uterus was unlikely. The hysteroscope, once inserted, had bubble-free fluid medium flowing. Therefore, the chance of room air embolism was minimal in this case.

Gaseous products of combustion are known to collect during endometrial ablation, and $\mathrm{CO}_{2}$ is a major component of this gas. ${ }^{12} \mathrm{CO}_{2}$ even though highly soluble, with a high safety profile ${ }^{17}$ has been reported by several authors to be the cause of gas embolism. ${ }^{18,19}$ Brandner et al. prospectively used Doppler sonography to detect both clinical and subclinical gas emboli during $\mathrm{CO}_{2}$ hysteroscopy. ${ }^{3}$ They concluded that air was the cause since flushing the tubing with $\mathrm{CO}_{2}$ prior to the procedure eliminated gas emboli detected by the Doppler. Following this report, Penny Gorton ${ }^{20}$ suggested that liquid distension medium would be associated with no risk of $\mathrm{CO}_{2}$ embolism since both $\mathrm{CO}_{2}$ and air would be eliminated. But given that the products of combustion $\left(\mathrm{CO}_{2}\right)$ can accumulate and embolize, use of a fluid medium cannot totally prevent this complication. The pressure within the uterus rises as fluid medium flows in, aiding the entry of gaseous products of combustion into the venous system. $\mathrm{CO}_{2}$ embolism has been reported to be short-lived because $\mathrm{CO}_{2}$ is highly soluble in blood $\left(54 \mathrm{~mL} \cdot \mathrm{dL}^{-1}\right){ }^{2,14}$

The time frame of adverse events in our patient is in keeping with our hypothesis that the products of combustion, particularly $\mathrm{CO}_{2}$, were responsible for the gas embolism. As surgery proceeded, and gaseous products collected, endometrial vessels were simultaneously disrupted and venous channels opened. The slight head down tilt and intra-uterine pressure provided the pressure gradient allowing the accumulated gas to rapidly enter the venous system. However, because $\mathrm{CO}_{2}$ is highly soluble, manual ventilation of the lungs with $100 \%$ oxygen was sufficient to support the patient until the $\mathrm{CO}_{2}$ was absorbed from the pulmonary circulation and normal $\mathrm{V} / \mathrm{Q}$ matching restored in the lungs.

In summary, we have presented a 50-yr-old woman who suffered a probable gas embolism during fluid medium operative hysteroscopy. Having taken precautions to prevent air embolism by gentle dilatation of the cervix, protection of the cervix and uterus from ambient air, and flushing air bubbles from the fluid medium, we believe gaseous products of combustion from the surgery, alongside venous channels opened by the surgery, and slight head down tilt, provided the circumstances which led to gas embolism. The prompt recovery of the vital signs points to a highly soluble gas such as $\mathrm{CO}_{2}$ as the cause.

\section{References}

1 Cooper JM, Brady RM. Intraoperative and early postoperative complications of operative steroscopy. Obstet Gynecol Clin North Am 2000; 27: 347-66.

2 Stoloff DR, Isenberg RA, Brill AI. Venous air and gas emboli in operative hysteroscopy. J Am Assoc Gynecol Laparosc 2001; 8: 181-92.

3 Brandner P, Neis KJ, Ehmer C. The etiology, frequen$\mathrm{cy}$, and prevention of gas embolism during CO2 hysteroscopy. J Am Assoc Gynecol Laparosc 1999; 6: 421-8.

4 Nachum Z, Kol S, Adir $\Upsilon$, Melamed $\Upsilon$. Massive air embolism-a possible cause of death after operative hysteroscopy using a $32 \%$ dextran-70 pump. Fertil Steril 1992; 58: 836-8.

5 Micheal $A$. Endometrial ablation and air embolism (Letter). Anaesth Intensive Care 1993; 21: 475.

6 Eugster D. Cardiac arrest during endometrial ablation (Letter). Anaesth Intensive Care 1993; 21: 891-2.

7 Wood SM, Roberts FL. Air embolism during transcervical resection of endometrium (Letter). BMJ 1990; 300: 945.

8 Loffer FD. Laser ablation of the endometrium. Obstet 
Gynecol Clin North Am 1988; 15: 77-89.

9 Perry PM, Baughman VL. A complication of hysteroscopy: air embolism. Anesthesiology 1990; 73: 546-7.

10 Baggish MS, Daniell JF. Death caused by air embolism associated with neodynium:yttrium-aluminum- garnet laser surgery and artificial sapphire tips. Am J Obstet Gynecol 1989; 161: 877-8.

11 Behnia R, Holley HS, Milad M. Successful early intervention in air embolism during hysteroscopy. J Clin Anesth 1997; 9: 248-50.

12 Gomar C, Fernandez C, Villalonga A, Nalda MA. Carbon dioxide embolism during laparoscopy and hysteroscopy. Ann Fr Anesth Reanim 1985; 4: 380-2.

13 Isaacson KB. Complications of hysteroscopy. Obstet Gynecol Clin North Am 1999; 26: 39-51.

14 Spencer MP, Oyama $\Upsilon$. Pulmonary capacity for dissipation of venous gas emboli. Aerospace Med 1971; 42: 822-7.

15 Brooks PG. Venous air embolism during operative hysteroscopy. J Am Assoc Gynecol Laparosc 1997; 4: 399-402.

16 Corson SL, Brooks PG, Soderstrom RM. Gynecologic endoscopic gas embolism. Fertil Steril 1996; 65: 529-33.

17 Corson SL, Hoffman JJ, Jackowski J, Chapman GA. Cardiopulmonary effects of direct venous $\mathrm{CO}_{2}$ insufflation in ewes. A model for $\mathrm{CO}_{2}$ hysteroscopy. J Reprod Med 1988; 33: 440-4.

18 Ditton JN. Presumed carbon dioxide embolism associated with hysteroscopy (Letter). Anaesth Intensive Care 1992; 20: 123-4.

19 Sherlock S, Shearer WA, Buist M, Rasiah R, Edwards A. Carbon dioxide embolism following diagnostic hysteroscopy. Anaesth Intensive Care 1998; 26: 674-6.

20 Gorton P. Hysteroscopy and gas embolism (Letter). Anaesth Intensive Care 1999; 27: 319. 